\title{
Towards standardization of training and practice of reconstructive microsurgery: an evidence-based recommendation for anastomosis thrombosis prophylaxis
}

\author{
Marie C. Kearns ${ }^{1,2} \cdot$ Jill Baker $^{1,3} \cdot$ Simon Myers $^{1} \cdot$ Ali Ghanem $^{1,4}$ (D)
}

Received: 8 February 2018 / Accepted: 28 March 2018 / Published online: 9 April 2018

(C) The Author(s) 2018

\begin{abstract}
Background Despite significant improvements in survival rates, free flap failures still occur even in experienced hands and are most commonly due to arterial or venous thrombosis. In the absence of an evidence-based guideline on the prevention of thrombosis, we reviewed the literature to assess the evidence base for commonly used interventions aimed at its prevention.

Methods A comprehensive literature search was performed using the following keywords "free flap" and microsurgery with "pre-operative screening," "prevention of thrombosis," "ketorolac," "heparin," "low molecular weight heparin," "aspirin," "dextran," and "statins."

Results Thirteen clinical studies were included in this review. No high-level evidence is available to support any perioperative or postoperative interventions aimed at reducing the risk of flap thrombosis.

Conclusions Higher level studies are needed to investigate the clinical use of antithrombotic medications in microsurgery; however, given the small failure rates in modern practice, these will need to be large multicenter trials in order to reach sufficient power. Level of Evidence: Level III, risk/prognostic study.
\end{abstract}

Keywords Microsurgery $\cdot$ Free flap surgery $\cdot$ Thrombosis $\cdot$ Heparin $\cdot$ Aspirin $\cdot$ Dextran

\section{Introduction}

Free flap reconstruction has seen vast improvements in survival rates over the past 30 years with success rates of $95-99 \%$ reported in the literature $[1,2]$. These advances are attributed to refinements in microsurgical technique, improvements in instruments, and patient selection. Meticulous technique and an experienced microsurgeon are commonly regarded as the key to success in free flap reconstruction. However, even in the hands of experts, failures do occur due to arterial or venous thrombosis. Patient factors that have been associated with an

Ali Ghanem

a.ghanem@qmul.ac.uk

1 Academic Plastic Surgery, Barts and the London School of Medicine and Dentistry, London, UK

2 Canniesburn Plastic Surgery Unit, Glasgow Royal Infirmary, Glasgow, UK

3 Department of Plastic Surgery, St John's Hospital, Livingston, West Lothian, UK

4 Centre for Cutaneous Research, Blizard Institute - Barts and The London School of Medicine, 4 Newark St, London E1 2AT, UK increased risk for free flap failure include atherosclerosis, obesity, presence of chronic wounds, and previous radiotherapy $[2,3]$. Free flap failure leads to delays to prolonged hospital stays, increased costs, delays in rehabilitation, and delays to adjuvant treatment for cancer patients. The surgeon is faced with planning an alternative method of reconstruction with possible challenges including a lack of recipient vessels, and the patient must deal with additional donor site morbidity and the psychological challenge of undertaking further surgery.

This article aims to review the current literature and propose an evidence-based approach to interventions aimed at minimizing the risks of thrombosis in free tissue transfer.

\section{Methods}

Searches were made of Medline, Embase, and Cochrane Library using the following search terms; microsurgery and free flap with anticoagulant, heparin, low molecular weight heparin, aspirin, dextran, statins, prevention of thrombosis, ketorolac, and preoperative screening. Titles and abstracts were reviewed to select papers suitable for full text review, and references of relevant articles were manually searched for 
relevant publications. Searches were guided by the PRISMA statement and searches were independently completed by MK and JB. Risk of bias was assessed using the Cochrane Risk of Bias Tool. Citations were managed using Endnote Version 7.

\section{Search strategy}

(microsurgery OR "free flap") AND (anticoagulant OR heparin OR aspirin OR "low molecular weight heparin" OR LMWH OR dextran OR statins OR ketorolac OR "prevention of thrombosis" OR "pre-operative screening")

Eligibility criteria (1) included patients 18 years of age or older, (2) included patients undergoing free flap reconstructive procedures, and (3) designed to assess the effect of a particular perioperative or postoperative intervention on the risk of pedicle thrombosis. Studies which did not include a comparative or control group, studies including less than 20 patients, and those with no English full text available were excluded. The primary outcomes were venous or arterial thrombosis, flap failure/survival, and return to theater.

\section{Results}

The literature search returned 493 results. Thirteen studies were included in this review which combined included 4668 free flaps. These included 1 level 1 study, 1 level 2 study, and 11 level 3 studies [4-16]. Interventions evaluated included aspirin, heparin (topical, intraoperative bolus and postoperative prophylactic dosing or infusion), low molecular weight heparin (LMWH), dextran, PGE1, ketorolac, and topical recombinant human tissue factor pathway inhibitor (rhTFPI). Four studies compared groups who were treated with a combination of anticoagulants, and 3/13 studies assessing the impact of anticoagulation had a negative control group which received no anticoagulation. Two included studies were published by the same group including the same series of patients $[6,7]$. One compares differences in thrombosis with an intraoperative bolus of heparin without detailing the differences in postoperative anticoagulation detailed in the other and vice versa.

The details of included studies are detailed in Table 1.

\section{Quantitative analysis}

Due to heterogeneity of dosing in all of these studies, lack of control studies, and combination regimes used in many studies, meta-analysis was not performed. Three studies assessed use of dextran 40; however, two of these studies included less than 25 patients treated with dextran and in one of these the dextran group 25 represented the first free flaps performed by that center.

\section{Discussion}

This systematic review highlights the difficulty in making evidence-based treatment decisions regarding prevention of pedicle thrombosis in free flap surgery. Treatment groups varied between groups undergoing free flap breast reconstruction $(n=1)$, head and neck reconstruction $(n=5)$, lower limb reconstruction $(n=1)$, and mixed $(n=6)$. In terms of anticoagulant drug treatments, doses and durations were highly varied causing difficulty in making direct comparisons between studies. Some studies were more than 20 years old, and flap failure rates may not be comparable with current rates of failure in high-volume centers. Others have attempted to perform meta-analysis in order to assess the impact of postoperative anticoagulation; however, we felt due to lack of homogeneity between treatments that this would not be desirable [17-19]. The majority of studies lacked a negative control group instead comparing with another drug and causing difficulty in assessing the true impact of each individual intervention. In addition, the most of these studies are retrospective, and a selection bias may exist in choosing which patients receive anticoagulants with common clinical practice being to start those patients on treatment when an intraoperative difficulty or problem is encountered. In the following discussion, we consider preoperative, perioperative, and postoperative factors that may affect pedicle thrombosis risk.

\section{Preoperative}

Senchenkov et al. describe preoperative screening for a hypercoagulable history and recommend a complex regime of aspirin, clopidogrel, dextran, and heparin based on this [20]. They describe excellent free flap success $(99.5 \%)$ in a retrospective case series of 355 free flaps the majority being for breast reconstruction. Those patients who received intraoperative anticoagulation had a hematoma rate of $27 \%$. The usefulness of this study is limited given its retrospective nature, the number of agents evaluated, the small number of patients identified preoperatively $(n=9)$, and the lack of a control arm. Nelson et al. described preoperative identification of hypercoagulable patients and use of a novel anticoagulation regime [8]. They report reduced incidence of arterial and venous thrombosis after its introduction in these high-risk patients, but the result does not reach statistical significance. These authors suggest risk stratifying patients in terms of thrombosis risk and tailoring perioperative anticoagulation dependent on risk. However, in the absence of a validated way of risk stratifying such patients, this is not straight forward and liaison with a hematologist may be beneficial when the patient is considered high risk.

There is no clear evidence that smoking increases the risk of microvascular thrombosis; however, patients should be advised to stop smoking in order to reduce their risk wound 


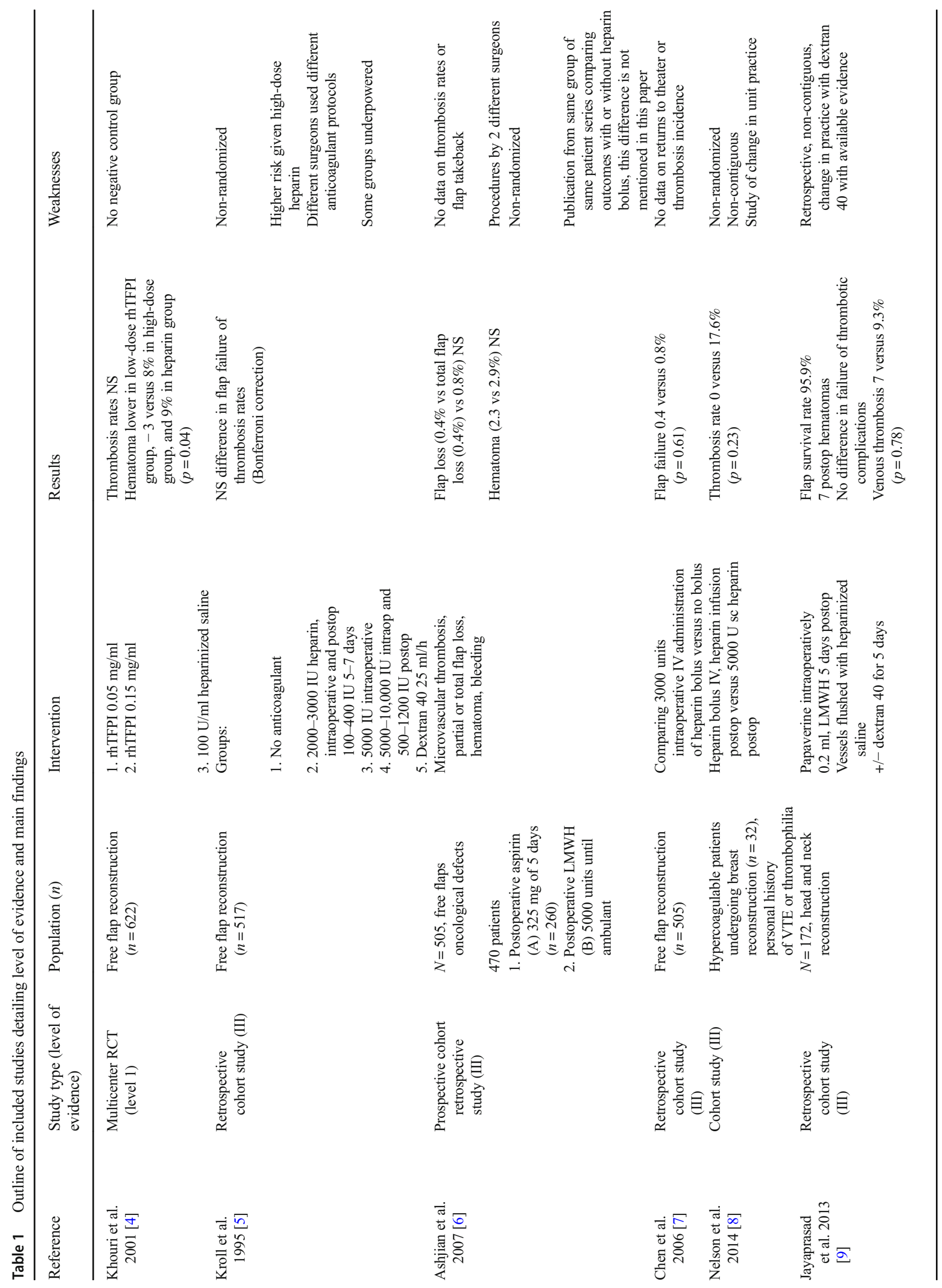




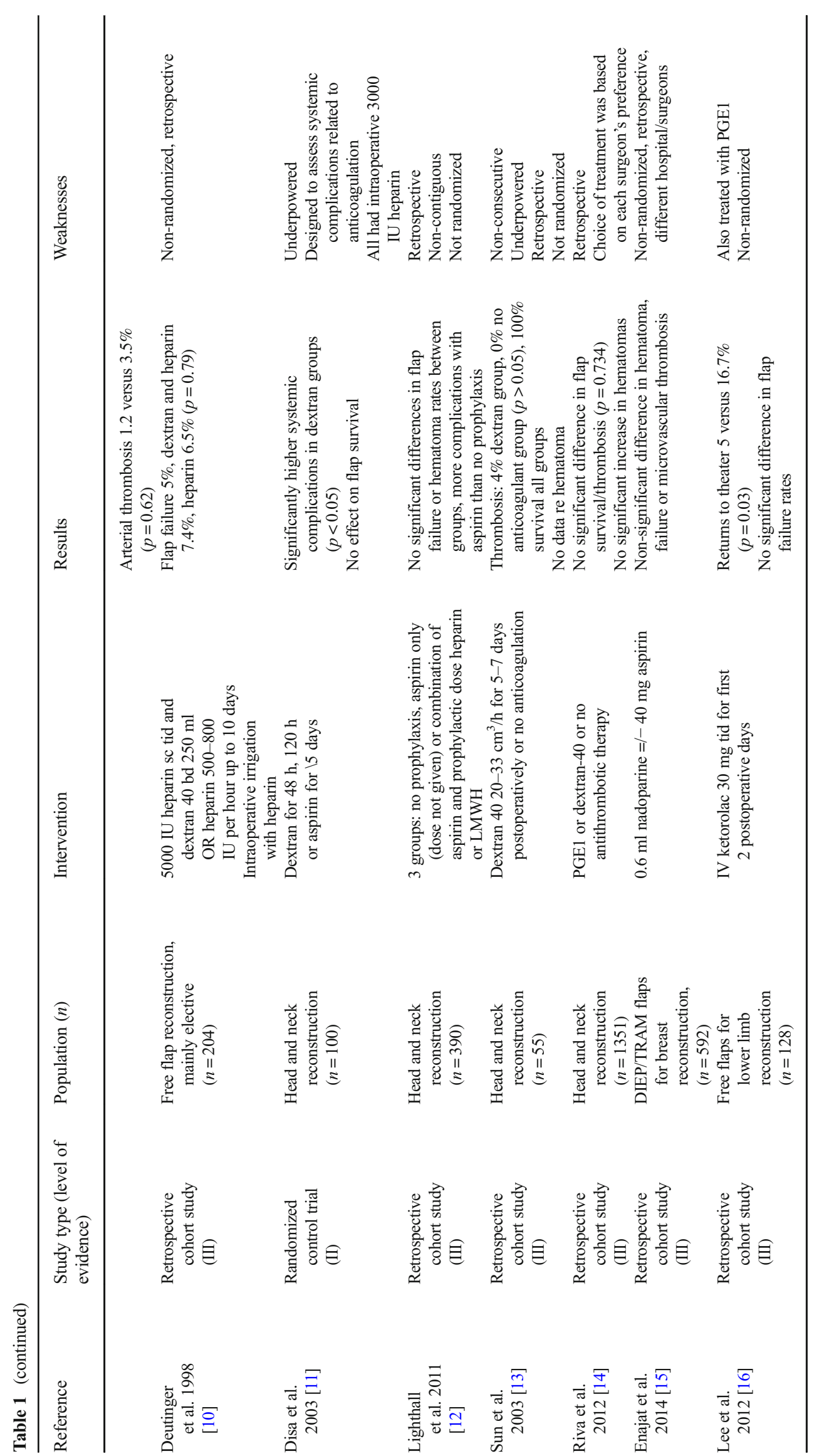


complications [21]. Tamoxifen has known prothrombotic effects and been shown to increase the risk of free flap failure when taken in the perioperative period [22]. Tamoxifen has a half-life of 2 weeks, and Mirzabeigi et al. found no increased risk of venous thromboembolism (VTE) or free flap failure in patients who ceased tamoxifen 2 weeks preoperatively [23]. As with other major surgeries, the oral contraceptive pill should be held preoperatively.

\section{Intraoperative}

\section{Surgical technique}

Delicate tissue handling and meticulous microsurgical technique are key to minimizing the risk of thrombosis. Seo et al. examined ten failed free flaps histologically and found all showed evidence of thrombus formation and endothelial injury [24]. Prompt recognition of thrombus formation intraoperatively is imperative, allowing the surgeon to remove the thrombus from the vessel and analyze local factors that may have attributed to the thrombus formation (vessel size mismatch, poor-quality recipient vessels, compression/twisting of anastomosis or pedicle) before considering the need to revise the anastomosis with or without a vein graft.

Venous couplers are used routinely by some surgeons for venous anastomoses allowing better eversion of the vessel ends and reducing operative and primary ischemia time. Disadvantages include high cost, reduced experience with hand-sewn microvascular anastomosis, and they are not suitable in all cases. Kulkarni et al. found a lower rate of venous thrombosis breast reconstruction cases with their use versus sutured venous anastomosis [25].

\section{Topical heparin}

In rat femoral artery models, topical vessel irrigation with heparinized saline has been shown to reduce thrombosis formation and be superior to systemically administered heparin both in terms of its antithrombotic effect and risk [26-28]. This effect has not been replicated in human studies. Limitations in these animal studies include the use of prothrombotic models (for example an intimal flap or crushing the vessel ends) and the use of junior microsurgeons as operators which makes them less reflective of clinical cases.

\section{Postoperative}

Routine use of antithrombotic drugs in microsurgery with the aim of preventing microvascular thrombosis has been reported to be as high as 96\% [29]. Great overlap exists between the use of anticoagulants to prevent postoperative VTE and to prevent flap thrombosis. A recent review by
Ricci et al. nicely addresses the evidence for VTE prevention in microvascular surgery. Recommendations include routine risk assessment using validated scores based on the Caprini system and use of both mechanical and chemoprophylaxis (40 mg enoxaparin or $5000 \mathrm{U}$ heparin daily) based on this [30].

\section{Heparin}

Heparin acts by inhibiting circulating thrombin, which is an essential factor in the coagulation cascade. Thrombin converts fibrinogen to fibrin, leading to formation of cross-linked fibrin, promotes platelet aggregation, and activates coagulation factors V and VIII [31]. Disadvantages of heparin use include cost of monitoring if maintained postoperatively and an unpredictable dose response.

Animal studies have shown that heparin can reduce thrombosis formation and improve flap viability when administered topically or systemically $[32,33]$. Clinical studies found no significant increase incidence of hematoma when low-dose heparin was administered at an appropriate dose for prevention of thromboembolism [5, 34]. No clinical studies demonstrated any benefit in the use of systemic heparin to prevent flap thrombosis.

\section{Low molecular weight heparin}

LMWH is produced by depolymerization of standard heparin into short polysaccharide fragments. LMWHs have the same inhibitory effect on activated factor X but have a weaker antithrombin activity. It is a standard prophylactic measure for venous thromboembolism for patients undergoing major surgery or those undergoing more minor surgery with risk factors for VTE. LMWH has shown varying results in animal studies in its ability to prevent thrombosis formation at microvascular anastomoses and no clear benefit in clinical studies [35, 36].

\section{Dextran}

Dextran, a polysaccharide, is produced by the action of the bacterium on sucrose. Dextran increases electronegative charge on platelets and endothelium therefore reducing platelet clumping. It promotes fibrin breakdown, activates plasminogen, decreases factor VIII and von Willebrand factor function therefore reducing platelet function, and acts as a volume expander. Associated side effects include pulmonary edema, renal failure, and anaphylaxis.

Ridha et al. published a study of UK plastic surgeons in 2005 and found that $45 \%$ routinely used dextran following microsurgical procedures [37]. They found no significant difference between success rates between those that did and those that did not use dextran. Dextran has largely fallen out 
Table 2 Evidence-based guidelines for prevention of pedicle thrombosis in free flap surgery

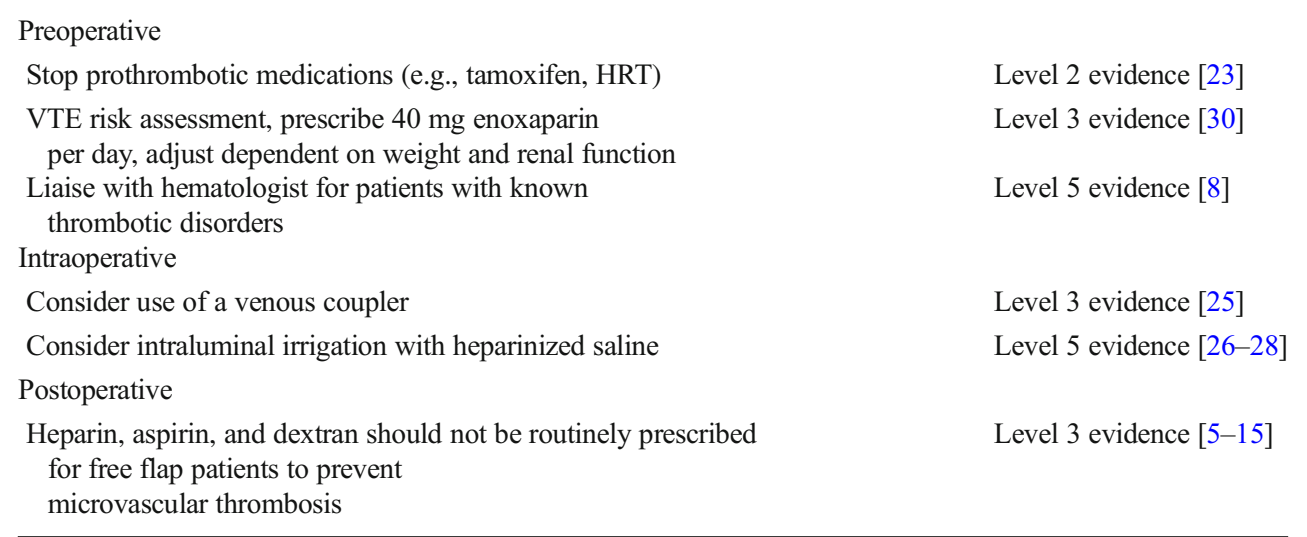

of favor due to potential risks of anaphylaxis and pulmonary edema and the lack of an evidence base to support its use.

\section{Aspirin}

Aspirin acts on the cyclooxygenase enzyme in platelets reducing production of thromboxane $\mathrm{A} 2$, in turn preventing platelet aggregation and vasoconstriction. It also decreases the endothelial production of prostacyclin. Associated side effects include gastric ulceration and increased bleeding.

Animal studies have shown that aspirin prevents platelet aggregation and thrombus development in microvascular anastomoses [38-40]. Other studies found no effect on final patency rates [41, 42]. Enajat et al. found no difference in thrombosis or flap failure but a higher hematoma rate in patients receiving aspirin following abdominal-based free flap breast reconstruction [15].

\section{Ketorolac}

Ketoralac which is a reversible cyclooxygenase inhibitor reduced platelet aggregation in addition to being an effective painkiller. Shufflebarger et al. found reduced rates of microvascular thrombosis in a prothrombotic rabbit model [43]. However, in the clinical study by Lee et al., although there were reduced returns to theater in the ketorolac-treated group, there was no difference in free flap failure rates [16].

Having reviewed the available evidence, we make the evidence-based recommendations detailed in Table 2 aiming to optimize the risks of thrombosis in free tissue transfer.

The regime proposed in this paper was based on analysis of current available evidence. With the lack of high-quality evidence, regime for optimizing the risk of thrombosis in free tissue transfer does not yet show consensus worldwide. It is widely accepted however that meticulous surgical technique is the key component to successful microsurgery. Further research in the form of high-quality randomized controlled trials is necessary to compare interventions aiming to target thrombosis.

\section{Conclusion}

There is no clinical evidence to support the routine use of anticoagulant or antiplatelet drugs in the postoperative period, and they may increase the risk of hematoma formation. There is a lack of randomized controlled trials investigating their use in free flap surgery, and given the current low rates of flap failures, designing such a trial which is suitably powered to find a difference in flap survival between patients would require an enrollment of greater than 1000 patients and would be most feasible on a multicenter international basis. Patients with a history of thrombosis may benefit from such treatments, but further research is needed in this area including a method of stratifying their risk of microvascular thrombosis (for example, the Caprini score could be investigated as a risk assessment tool for flap thrombosis). Given these patients have a much higher risk of flap thrombosis, a randomized controlled trial may be worthwhile in this subgroup of patients.

\section{Compliance with ethical standards}

Conflict of interest Marie C. Kearns, Jill Baker, Simon Myers, Ali Ghanem declare that they have no conflict of interest.

Funding No funding was received in relation to this work.

Informed consent Not applicable, no patients involved in this study.

Ethical approval Not required.

Open Access This article is distributed under the terms of the Creative Commons Attribution 4.0 International License (http:// creativecommons.org/licenses/by/4.0/), which permits unrestricted use, distribution, and reproduction in any medium, provided you give appropriate credit to the original author(s) and the source, provide a link to the Creative Commons license, and indicate if changes were made. 


\section{References}

1. Mahmoudi E, Lu Y, Chang SC, Lin CY, Wang YC, Chang CJ, Cheng MH, Chung KC (2017) Associations of surgeon and hospital volumes with outcome for free tissue transfer by using the National Taiwan Population Health Care data from 2001 to 2012. Plast Reconstr Surg 140(3):455e-465e

2. Ishimaru M, Ono S, Suzuki S, Matsui H, Fushimi K, Yasunaga H (2016) Risk factors for free flap failure in 2,846 patients with head and neck cancer: a national database study in Japan. J Oral Maxillofac Surg 74(6):1265-1270

3. Sanati-Mehrizy P, Massenburg BB, Rozehnal JM, Ingargiola MJ, Hernandez Rosa J, Taub PJ (2016) Risk factors leading to free flap failure: analysis from the National Surgical Quality Improvement Program Database. J Craniofac Surg 27(8):1956-1964

4. Khouri RK, Sherman R, Buncke HJ Jr, Feller AM, Hovius S, Benes CO, Ingram DM, Natarajan NN, Sherman JW, Yeramian PD, Cooley BC (2001) A phase II trial of intraluminal irrigation with recombinant human tissue factor pathway inhibitor to prevent thrombosis in free flap surgery. Plast Reconstr Surg 107(2):408415 discussion 416-8

5. Kroll SS, Miller MJ, Reece GP, Baldwin BJ, Robb GL, Bengtson BP, Phillips MD, Kim D, Schusterman MA (1995) Anticoagulants and hematomas in free flap surgery. Plast Reconstr Surg 96(3):643647

6. Ashjian P, Chen CM, Pusic A, Disa JJ, Cordeiro PG, Mehrara BJ (2007) The effect of postoperative anticoagulation on microvascular thrombosis. Ann Plast Surg 59(1):36-39 discussion 39-40

7. Chen CM, Ashjian P, Disa JJ, Cordeiro PG, Pusic AL, Mehrara BJ (2008) Is the use of intraoperative heparin safe? Plast Reconstr Surg 121(3):49e-53e

8. J.A. Nelson, C.U. Chung, A.R. Bauder, L.C. Wu, Prevention of thrombosis in hypercoagulable patients undergoing microsurgery: a novel anticoagulation protocol, J Plast Reconstr Aesthet Surg 70(3) (2017) 307-312

9. Jayaprasad K, Mathew J, Thankappan K, Sharma M, Duraisamy S, Rajan S, Paul J, Iyer S (2013) Safety and efficacy of low molecular weight dextran (dextran 40) in head and neck free flap reconstruction. J Reconstr Microsurg 29(7):443-448

10. Deutinger M, Rath T, Constantinou E, Schneider B (1998) The influence of postoperative medical treatment and type of microvascular anastomosis on free tissue transfer. Eur J Plast Surg 21(6): 273-276

11. Disa JJ, Polvora VP, Pusic AL, Singh B, Cordeiro PG (2003) Dextran-related complications in head and neck microsurgery: do the benefits outweigh the risks? A prospective randomized analysis. Plast Reconstr Surg 112(6):1534-1539

12. Lighthall JG, Bell RA, Wax MK, Ghanem TAH (2011) Role of postoperative aspirin in free tissue transfer. Otolaryngol Head Neck Surg 145:143

13. Sun TB, Chien SH, Lee JT, Cheng LF, Hsu LP, Chen PR (2003) Is dextran infusion as an antithrombotic agent necessary in microvascular reconstruction of the upper aerodigestive tract? J Reconstr Microsurg 19(7):463-466

14. Riva FMG, Chen YC, Tan NC, Lin PY, Tsai YT, Chang HW, Kuo YR (2012) The outcome of prostaglandin-E1 and dextran-40 compared to no antithrombotic therapy in head and neck free tissue transfer: analysis of 1,351 cases in a single center. Microsurgery 32(5):339-343

15. Enajat M, Aziz Mohammadi M, Debeij J, van der Hulst RR, Mureau MA (2014) Effect of acetylsalicylic acid on microvascular thrombosis in autologous breast reconstruction. J Reconstr Microsurg 30(1):65-70

16. K.T. Lee, B.J. Jeon, S.Y. Lim, J.K. Pyon, S.I. Bang, K.S. Oh, G.H. Mun, The effects of ketorolac on microvascular thrombosis in lower extremity reconstruction, Plast Reconstr Surg 129(6) (2012) 1322 1327

17. Lee KT, Mun GH (2015) The efficacy of postoperative antithrombotics in free flap surgery: a systematic review and meta-analysis. Plast Reconstr Surg 135(4):1124-1139

18. Pan XL, Chen GX, Shao HW, Han CM, Zhang LP, Zhi LZ (2014) Effect of heparin on prevention of flap loss in microsurgical free flap transfer: a meta-analysis. PLoS One 9(4):e95111

19. Liu J, Shi Q, Yang S, Liu B, Guo B, Xu J (2018) Does postoperative anticoagulation therapy lead to a higher success rate for microvascular free-tissue transfer in the head and neck? A systematic review and meta-analysis. J Reconstr Microsurg 34(2):87-94

20. Senchenkov A, Lemaine V, Tran NV (2015) Management of perioperative microvascular thrombotic complications - the use of multiagent anticoagulation algorithm in 395 consecutive free flaps. J Plast Reconstr Aesthet Surg 68(9):1293-1303

21. Chang DW, Reece GP, Wang B, Robb GL, Miller MJ, Evans GR, Langstein HN, Kroll SS (2000) Effect of smoking on complications in patients undergoing free TRAM flap breast reconstruction. Plast Reconstr Surg 105(7):2374-2380

22. Kelley BP, Valero V, Yi M, Kronowitz SJ (2012) Tamoxifen increases the risk of microvascular flap complications in patients undergoing microvascular breast reconstruction. Plast Reconstr Surg 129(2):305-314

23. Mirzabeigi MN, Nelson JA, Fischer JP, Kovach SJ, Serletti JM, Wu LC, Kanchwala S (2015) Tamoxifen (selective estrogen-receptor modulators) and aromatase inhibitors as potential perioperative thrombotic risk factors in free flap breast reconstruction. Plast Reconstr Surg 135(4):670e-679e

24. Seo MH, Kim SM, Huan F, Myoung H, Lee JH, Lee SK (2015) Analysis of microvascular free flap failure focusing on the microscopic findings of the anastomosed vessels. J Craniofac Surg 26(7): 2047-2051

25. Kulkarni AR, Mehrara BJ, Pusic AL, Cordeiro PG, Matros E, McCarthy CM, Disa JJ (2015) Venous thrombosis in handsewn versus coupled venous anastomoses in 857 consecutive breast free flaps. J Reconstr Microsurg 32(3):178-182

26. Cox GW, Runnels S, Hsu HS, Das SK (1992) A comparison of heparinised saline irrigation solutions in a model of microvascular thrombosis. Br J Plast Surg 45(5):345-348

27. Chen LE, Seaber AV, Korompilias AV, Urbaniak JR (1995) Effects of enoxaparin, standard heparin, and streptokinase on the patency of anastomoses in severely crushed arteries. Microsurgery 16(10): 661-665

28. Andresen DM, Barker JH, Hjortdal VE (2002) Local heparin is superior to systemic heparin in preventing arterial thrombosis. Microsurgery 22(6):265-272

29. Glicksman A, Ferder M, Casale P, Posner J, Kim R, Strauch B (1997) 1457 years of microsurgical experience. Plast Reconstr Surg 100(2):355-363

30. Ricci JA, Crawford K, Ho OA, Lee BT, Patel KM, Iorio ML (2016) Practical guidelines for venous thromboembolism prophylaxis in free tissue transfer. Plast Reconstr Surg 138(5):1120-1131

31. Esclamado RM, Carroll WR (1999) The pathogenesis of vascular thrombosis and its impact in microvascular surgery. Head Neck 21(4):355-362

32. Hudson DA, Engelbrecht G, Duminy FJ (2000) Another method to prevent venous thrombosis in microsurgery: an in situ venous catheter. Plast Reconstr Surg 105(3):999-1003

33. Savoie FH, Cooley BC, Gould JS (1991) Evaluation of the effect of pharmacologic agents on crush-avulsion arterial injuries: a scanning electron microscopy study. Microsurgery 12(4):292-300

34. Liao EC, Taghinia AH, Nguyen LP, Yueh JH, May JW, Orgill DP (2008) Incidence of hematoma complication with heparin venous thrombosis prophylaxis after TRAM flap breast reconstruction. Plast Reconstr Surg 121(4):1101-1107 
35. Yousef MA, Dionigi P (2015) Experimental thromboprophylaxis with low molecular weight heparin after microsurgical revascularization. J Hand Microsurg 7(2):256-260

36. Murthy P, Riesberg MV, Hart S, Bustillo A, Duque CS, Said S, Civantos FJ (2003) Efficacy of perioperative thromboprophylactic agents in the maintenance of anastamotic patency and survival of rat microvascular free groin flaps. Otolaryngol Head Neck Surg 129(3):176-182

37. Ridha H, Jallali N, Butler PE (2006) The use of dextran post free tissue transfer. J Plast Reconstr Aesthet Surg 59(9):951-954

38. F.W. Peter, R.J. Franken, W.Z. Wang, G.L. Anderson, D.A. Schuschke, M.M. O'Shaughnessy, J.C. Banis, H.U. Steinau, J.H. Barker, Effect of low dose aspirin on thrombus formation at arterial and venous microanastomoses and on the tissue microcirculation, Plast Reconstr Surg 99(4) (1997) 1112-1121

39. Cooley BC, Ruas EJ, Wilgis EF (1987) Scanning electron microscopy of crush/avulsion arterial trauma: effect of heparin and aspirin administration. Microsurgery 8(1):11-16
40. Chung TL, Pumplin DW, Holton LH 3rd, Taylor JA, Rodriguez ED, Silverman RP (2007) Prevention of microsurgical anastomotic thrombosis using aspirin, heparin, and the glycoprotein IIb/IIIa inhibitor tirofiban. Plast Reconstr Surg 120(5):1281-1288

41. Buckley RC, Davidson SF, Das SK (1994) The role of various antithrombotic agents in microvascular surgery. Br J Plast Surg 47(1):20-23

42. Basile AP, Fiala TG, Yaremchuk MJ, May JW Jr (1995) The antithrombotic effects of ticlopidine and aspirin in a microvascular thrombogenic model. Plast Reconstr Surg 95(7):1258-1264

43. Shufflebarger JV, Doyle J, Roth T, Maguire K, Rothkopf DM (1996) The effect of ketorolac on microvascular thrombosis in an experimental rabbit model. Plast Reconstr Surg 98(1):140-145 